\section{Switching from the bio-originators to biosimilar: is it premature to recommend this procedure?}

We read with interest the recently published recommendations for the use of biosimilars in rheumatology practice. ${ }^{1}$ However, we have some concerns regarding recommendation 6 on the efficacy and safety of switching from the originator biologic to the respective biosimilar. Considering the strong impact of the European League Against Rheumatism recommendations on real-life clinical decisions, such recommendation seems not sufficiently supported by the evidence because available data do not allow to draw definitive conclusion on the switching strategy. To date, the efficacy and safety of infliximab and etanercept biosimilars in substitution of the bio-originators have been assessed in four long-term extension reports following the blinded phase of the respective randomised controlled trials (RCTs), ${ }^{2-5}$ but the transposition of these results to the real-life practice seems rather questionable. Indeed, patients treated in the setting of real-world practice greatly differ from those enrolled in clinical trials, as suggested by an analysis from the German Rheumatoid Arthritis: Observation of Biologic Therapy (RABBIT) registry showing that only $21 \%-33 \%$ of the included patients would have been eligible for RCTs. ${ }^{6}$ Also the results of the Norwegian Switch study (NOR-SWITCH) trial do not adequately support the switching strategy from infliximab originator (re-IFX) to infliximab biosimilar (bio-IFX) in patients with inflammatory rheumatic diseases because only 198 (41\%) out of 481 enrolled patients had a rheumatic disorder, including 91 (18.9\%) spondyloarthritis (SpA), 77 (16\%) rheumatoid arthritis (RA) and 30 (6.2\%) psoriatic arthritis (PsA). ${ }^{7}$ Consequently, the study lacks of statistical power with important repercussion on the clinical significance of the results in patients with SpA, RA and PsA. The Danish Nationwide Biologic (DANBIO) registry reported data from a large series of 802 patients with RA, SpA and PsA who were switched from re-IFX to bio-IFX. ${ }^{8}$ No negative impact of bio-IFX on the disease activity was recorded, but the retention rate was significantly lower as compared with a historical cohort of patients receiving re-IFX (86.8\% vs $83.4 \%$; P: 0.03$)$. Similar findings have been recently observed in other clinical series from Turkey. ${ }^{9}$

Data from the DANBIO registry on the switching from originator etanercept (re-ETN) to biosimilar etanercept (bio-ETN) were recently presented. ${ }^{10}$ At the end of the follow-up period, bio-ETN was withdrawn in 129 (8.3\%) out of 1548 patients who were in clinical remission prior to the switching. Confirming the different clinical characteristics of patients treated in real-life practice, despite a shorter follow-up duration of 5 months, the percentage of withdrawals was higher than in the study of Emery and colleagues ${ }^{4}(5 \%$ over 48 weeks). In this sense, the paucity of data from real life and the absence of controlled trials suggest that also recommendation 7 (evidence level 5 and degree of recommendation $\mathrm{D})^{1}$ may be misleading for clinicians, who may be driven by health authorities to choices made only on an economic basis.

To conclude, in our opinion, available data from real-world clinical practice, somewhat conflicting with those of RCTs, seem to suggest that it is premature to formulate recommendations on the switching strategy from the bio-originator to its biosimilar.

\section{Fabrizio Cantini, ${ }^{1}$ Maurizio Benucci ${ }^{2}$}

${ }^{1}$ Department Rheumatology, Azienda USL Toscana Centro, Hospital of Prato, Prato, Italy

${ }^{2}$ Rheumatology Clinic, Azienda USL Toscana Centro, Nuovo S Giovanni di Dio Hospital, Florence, Italy

Correspondence to Dr Fabrizio Cantini, Department Rheumatology, Azienda USL Toscana Centro, Hospital of Prato, Prato 59100, Italy; fbrzcantini@gmail.com

Handling editor Josef S Smolen

Contributors $\mathrm{FC}$ and $\mathrm{MB}$ equally contributed to writing the manuscript. Competing interests None declared.

Provenance and peer review Not commissioned; internally peer reviewed.

(c) Article author(s) (or their employer(s) unless otherwise stated in the text of the article) 2019. All rights reserved. No commercial use is permitted unless otherwise expressly granted.

\section{Check for updates}

To cite Cantini F, Benucci M. Ann Rheum Dis 2019;78:e23.

Received 9 December 2017

Accepted 15 December 2017

Published Online First 29 December 2017

Ann Rheum Dis 2019;78:e23. doi:10.1136/annrheumdis-2017-212820

\section{REFERENCES}

1 Kay J, Schoels MM, Dörner T, et al. Task Force on the Use of Biosimilars to Treat Rheumatological Diseases. Consensus-based recommendations for the use of biosimilars to treat rheumatological diseases. Ann Rheum Dis 2018;77:165-74.

2 Yoo DH, Prodanovic N, Jaworski J, et al. Efficacy and safety of CT-P13 (biosimilar infliximab) in patients with rheumatoid arthritis: comparison between switching from reference infliximab to CT-P13 and continuing CT-P13 in the PLANETRA extension study. Ann Rheum Dis 2017;76:355-63.

3 Park W, Yoo DH, Miranda P, et al. Efficacy and safety of switching from reference infliximab to CT-P13 compared with maintenance of CT-P13 in ankylosing spondylitis: 102-week data from the PLANETAS extension study. Ann Rheum Dis 2017;76:346-54

4 Emery P, Vencovský J, Sylwestrzak A, et al. Long-term efficacy and safety in patients with rheumatoid arthritis continuing on SB4 or switching from reference etanercept to SB4. Ann Rheum Dis 2017;76:1986-91.

5 Tanaka Y, Yamanaka H, Takeuchi T, et al. Safety and efficacy of CT-P13 in Japanese patients with rheumatoid arthritis in an extension phase or after switching from infliximab. Mod Rheumatol 2017;27:237-45.

6 Zink A, Strangfeld A, Schneider M, et al. Effectiveness of tumor necrosis factor inhibitors in rheumatoid arthritis in an observational cohort study: comparison of patients according to their eligibility for major randomized clinical trials. Arthritis Rheum 2006;54:3399-407.

7 Jørgensen $\mathrm{KK}$, Olsen IC, Goll GL, et al. Switching from originator infliximab to biosimilar CT-P13 compared with maintained treatment with originator infliximab (NOR-SWITCH): a 52-week, randomised, double-blind, non-inferiority trial. Lancet 2017;389:2304-16.

8 Glintborg B, Sørensen IJ, Loft AG, et al. A nationwide non-medical switch from originator infliximab to biosimilar CT-P13 in 802 patients with inflammatory arthritis: 1-year clinical outcomes from the DANBIO registry. Ann Rheum Dis 2017;76:1426-31.

9 Yazici Y, XieL OA, Parenti D, et al. A descriptive analysis of real-world treatment patterns of innovator infliximab (Remicade) and biosimilar infliximab in a treatment naïve Turkish rheumatologic disease population. 2017 EULAR meeting poster session FRI0211, Madrid, Spain. Ann Rheum Dis 2017;76(Suppl 2):562.

10 Glintborg B,Sørensen IJ, Loft AG, Esbesen J, et al. Clinical outcomes from a nationwide non-medical switch from originator to biosimilar etanercept in patients with inflammatory arthritis after 5 months follow-up. Results from the DANBIO registry. Ann Rheum Dis 2017;76(Suppl 2):553. 